\title{
MUNDO DA VIDA E DIREITO NATURAL Uma fundamentação fenomenológica dos Direitos Humanos?
}

\author{
Ana Paula Loureiro de Sousa \\ Centro de Filosofia da UL \\ Universidade Lusófona
}

1. A situação de barbárie e de violência que se viveu na II Grande Guerra, assim como o desenvolvimento tecnológico e consequente globalização, geraram uma crise no interior do direito que tem como consequência repensá-lo não apenas numa perspectiva ontológica e normativa, mas também axiológica. A questão incontornável que se coloca agora é pelo sentido de sentido do direito, a qual não prescinde de uma atenta reflexão sobre o homem, a intersubjetividade e os seus modos de vida política e comunitária. Nessa linha, a Declaração Universal dos Direitos do Homem, de 1948 (DH), constitui-se como um diálogo intercultural de garantia de proteção de direitos, os quais radicam na dignidade "inerente a todos os membros da família humana". Estabelece o propósito de promover uma "concepção comum" para "todos os povos e todas as nações", com o firn de alcançar um mundo onde os homens sejam "livres de falar e de crer, libertos do terror e da miséria [...]". ${ }^{1}$

Sem olvidar as primeiras proclamações dos $\mathrm{DH}$, foi a Declaração de 1948 que pôs, novamente, no terreno político, social, moral, e, até, no quotidiano, o discurso sobre os $\mathrm{DH}$, dando origem, posteriormente, a outras declarações, protocolos e convénios. Podemos, por isso, afirmar que estamos no tempo dos Direitos Humanos, ainda que o discurso sobre eles, e o próprio termo $\mathrm{DH}$, se revele, bastas vezes, complexo e ambíguo, conduzindo a múltiplas interpretações. Aliás, este problema tem sido muito controvertido, pelo que nem de

${ }^{1}$ Declaração Universal dos Direitos do Homem, aprovada e proclamada pela Assembleia Geral das Nações Unidas na sua resolução 217 A (III), de 10 de Dezembro de 1948. 
longe nos iremos ocupar dele em extensão. No entanto, não deixamos de fazer uma pergunta diretora: serão os $\mathrm{DH}$ direitos naturais que fazem parte constituinte do direito? Estamos em crer que sim.

O trajeto que vamos percorrer é feito com a fenomenologia. Ela fornece-nos instrumentos de análise que nos permitem compreender em que medida os $\mathrm{DH}$ se podem relacionar com o Direito Natural. Tais instrumentos dizem respeito à fenomenologia do mundo da vida, à noção de pré-doação, à descrição fenomenológica da intersubjetividade e, finalmente, à noção ética de responsabilidade.

Os textos husserlianos que tomamos como referência são: $A$ Crise das Ciências Europeias e a Fenomenologia Transcendental. Uma introdução à Filosofia Fenomenológica; Ideias para uma Fenomenologia Pura e para uma Filosofia Fenomenológica; Cinco Artigos sobre Renovação; A crise da Humanidade Europeia e a Filosofia; Meditações Cartesianas - $V^{a}$ Meditação. ${ }^{2}$

Mas a fenomenologia, como "método de crítica do conhecimento", não nos oferece respostas expressas para o problema da relação entre direitos humanos e direito natural. Por isso, não se espere também destas reflexões uma conclusão definitiva, mas, ao invés, o que aqui deixamos são breves considerações que nos direcionam para a seguinte questão de fundo: pode o direito natural constituir fundamento da normatividade? Pode a descrição fenomenológica da intersubjetividade servir de base para assentar sobre ela uma teoria dos direitos humanos? Em que ponto emerge o direito como categoria da intersubjetividade?

2. A primeira ideia que queremos salientar é aquela que o método fenomenológico exige, o retorno às coisas mesmas, ou seja, às instituições originárias de sentido nas quais os objetos se constituem. Temos de volver à subjetividade transcendental através da qual se constitui uma experiência do mundo, envolvendo os estratos da naturalidade, da intersubjetividade, da sociabilidade e, mais além dela, da vida em comunidade, com os seus objetos respectivos, a saber, as instituições do mundo social e comunitário, e os indivíduos, enquanto pessoas em mútua apreensão e em mútuo reconhecimento. É pelo método da parentetização que procede a epoché fenomenológica, segundo a qual se suspende a tese da atitude natural.

Escreve Husserl: "a epoché é uma alteração radical [...]. Com esta libertação, e nela, é dada a descoberta da correlação universal, inteiramente encer-

2 Seguimos a tradução portuguesa: Phainomenon, Centro de Filosofia da Faculdade de Letras da Universidade de Lisboa. 
rada em si e absolutamente autónoma, do próprio mundo e da consciência do mundo". 3

Esta "descoberta da correlação universal" é compreendida segundo a redução transcendental. Nesta, o sujeito é sujeito para o mundo, é o "eu puro" e o tecido da sua vida intencional. Este "eu puro" é o ser próprio da consciência, através do qual se dá a autorreflexão, que objetiva e tematiza as vivências purificadas (libertas da apercepção mundana), nas quais se efetua a "doação originária de sentido". Portanto, a função da redução transcendental é tornar patente a correlação entre ato intencional e noema objetual. Ora, como sabemos pelas obras do último Husserl, o estrato mais básico da constituição mundana é a fenomenologia do mundo da vida.

Segundo o autor, "O mundo da vida é [...], para nós os que vivemos, aquilo que existe sempre já de antemão, o «solo» para toda a práxis, tanto teorética quanto extrateorética. Para nós, sujeitos [...], continuamente, e de um modo ou outro, [...] o mundo é pré-dado como horizonte, não por uma vez, ocasionalmente, mas sempre e necessariamente, como campo universal de toda a práxis efetiva e possível".

O mundo da vida é, assim, a pré-doação universal para toda a experiência, tanto teórica, como prática, como socialmente orientada em atos de correlação intersubjetiva.

Isto tem um duplo significado. O mundo da vida dá-se com o sentido de algo que está já sempre de antemão, antes de quaisquer atos e de qualquer atividade prática ou teórica, ele é o que está sempre aí, aquele em que estamos inseridos, é o "viver na certeza-do-mundo". Mas não basta isto. É preciso ter a consciência de que vivemos no mundo e que percepcionamos o mundo como estando sempre já aí de antemão, como algo em que a nossa vida se insere. A consciência do mundo está em sermos conscientes das coisas como "objetos no horizonte do mundo". Dito de outro modo, temos, consciência do mundo como horizonte total no qual inscrevemos os nossos atos e seus objetos correlativos. ${ }^{4}$ Portanto, cada ente participa de múltiplos horizontes - internos e externos - que se inscrevem nesse horizonte total do mundo.

Dentro desta orientação, não podemos deixar de mencionar o conceito de pré-doação. Na verdade, enquanto mundo pré-dado, é o horizonte total, engloba num continuum todas as "metas", realizadas e a realizar, provisórias ou constantes. A pré-doação é o "solo" que constitui aquilo a que chamamos mundo. "Mundo é o campo universal para onde estão dirigidos todos

4 Hua VI, 157. 
os nossos atos de experiência, de conhecimento ou de ação", escreve Husserl. ${ }^{5}$ Assim, a pré-doação tem que ver com estruturas de sentido que são prévias à intencionalidade ativa. Para o que nos interessa, tem que ver com um sentido que antecede os atos que se exprimem sob forma proposicional, como é o caso dos juízos teóricos e das normas de direito. Do mesmo modo, o mundo da vida tem múltiplas camadas. Advertimos que o mundo da vida, para lá da esfera fundante da naturalidade, contém também a pré-doação intersubjectiva e a dinâmica da socialidade. Interessa-nos especialmente estas últimas dimensões da pré-doação do mundo como horizonte universal, ou seja, a relação com um alter ego e a socialidade. Assim, o mundo da vida é por nós entendido como mundo intersubjetivo e, como veremos adiante, será no estrato da "região cultura" que se virá inserir o Direito

Por conseguinte, antes de qualquer ato normativo, há sempre algo que, para ele, se dá com o sentido de estar "já lá de antemão". Ou seja, o horizonte da norma é esse "fundo" de sentido prévio ao ato normativo. Então impõe-se uma pergunta: que horizonte é esse?

Comecemos, então, pela redução fenomenológica. Segundo o método da parentetização, pomos "fora de circuito" o mundo jurídico como fato, e suspendemos toda a ciência positiva do direito, ou seja, pomo-los, ao mundo jurídico e à ciência jurídica, fora de validade. O que nos fica dessa redução? A boa resposta husserliana é: fica-nos o "fenómeno-Direito", como correlato da consciência intencional originariamente constituinte, ou seja, fica-nos o tecido de prestações intencionais em que algo como o Direito se constitui enquanto tal. Aqui, a consciência intencional dirá respeito aos atos originariamente doadores do sentido da juridicidade, constituindo o priori jurídico enquanto tal, a partir de uma pré-doação de sentido passiva, que é o horizonte em que se insere a constituição ativa do mundo normativo, horizonte esse que já encerra a constituição ativa do estrato de sentido da simples natureza. Assim, a redução transcendental conduz-nos ao eidos-direito, ou ao direito como essência regional. A finalidade desta marcha será definir as condições de possibilidade de todo e qualquer sistema jurídico positivo, circunscrevendo os limites a partir dos quais os sistemas jurídicos deixariam de ser possíveis pela exibição tanto dos estratos em que ele está fundado (por exemplo, a naturalidade e a intersubjetividade), como das leis de essência que caracterizam o eidos-Direito na sua especificidade.

Chegados aqui, estamos habilitados a descrever as estruturas dos atos que se exprimem de forma proposicional, do qual fazem parte as normas. Para tal, é imperioso considerarmos a noção de intersubjetividade e de vida

5 Hua VI, 158. 
comunitária. Justamente, é sobre a intersubjetividade e a vida comunitária que se alicerça a essência do Direito.

3. Os homens estão inevitavelmente em coexistência, seja esta pacífica, seja dada pelo confronto. Isolados, jamais poderiam manifestar a sua humanidade, pois esta dá-se através das relações de convivência. Basta pensar no caso das crianças selvagens para percebermos como, isolados do contexto social e cultural, a nossa humanidade fica reduzida. Sustentamos, portanto, que a condição de coexistência, é estruturante de toda a intersujetividade e, consequentemente, prévia a toda a norma, seja esta entendida como prescritiva, proibitiva declarativa ou comando, seja uma norma moral ou de outro tipo.

$\mathrm{Na}$ verdade, um dos sentidos da apercepção de um outro sujeito é o ele dar-se com o sentido de "estranho", "alheio". Mas estranho, Fremd, não significa inimigo, Feind. Se o sentido originário da doação de um outro sujeito é a estranheza, como o mostrou Husserl, essa estranheza não se volve ainda em hostilidade, à maneira de Schmitt. Nessa medida, a relação intersubjetiva, como acolhimento do que me é estranho, mas que é um outro como eu, envolve a condição de coexistência como sua dimensão estruturante.

Uma teoria da constituição, conjugada com a génese passiva, são os elementos que melhor explicam as estruturas essenciais dessa condição.

A primeira intuição que tenho de mim mesmo está em encontrar-me de antemão como um ego que se localiza "num ambiente que está «aí para mim »" " feito de outros eus, bem como de coisas, que estão disponíveis «para mim»s. Outros eus e objetos disponíveis fazem parte do meu horizonte do mundo, tal como eu próprio, que me dou conta daquilo que sou por um modo de auto-acesso que envolve os modos como me encontro de antemão já presente no horizonte do mundo.

E a experiência primeira que o meu ego tem de si próprio é, neste contexto, a de um soma (Leib) animado por uma psique. Com efeito, é no mundo circundante que irrompe o meu corpo, como corpo de um ego monádico espácio-temporalmente localizado. Nesta medida, só porquanto apareço corporalmente no mundo me é dada a aparição de outrem, sendo eu, reciprocamente, uma aparição para o outro. Significa isto que o outro tem experiência de mim pelo seu soma, na medida em que projeta no meu soma a sua experiência da corporalidade própria.

Nesta co-presença, ou neste emparelhamento, como o denomina Husserl, o ego inter-relaciona-se com o alter ego por uma associação, ou síntese de analogia, a partir da qual dá sentido aos gestos, que agora já não são meros

${ }^{6}$ Husserl, Meditações Cartesianas. $V^{a}$ Meditação. Porto: Ed. Rés p. 91. 
movimentos corporais, mas expressões de sentimentos, vontades, expetativas, frustrações. Aceitamos que temos já uma comunidade "quando existimos mutuamente uns para os outros no mundo circundante (o outro, no meu), o que implica, sempre, existir somático-corporeamente". ${ }^{7}$ Mas a comunidade aprofunda-se através das relações de mútua compreensão e de cooperação. Desta dialética forma-se aquilo que se designa fenomenologicamente como "atos de consciência «sociais»", os quais originam uma forma de comunidade "espiritualmente unida por momentos internos, através de atos e de motivações intersubjetivos". 8

É neste momento básico, no sentido de primeiro, que se dá a consciência da especificidade própria das comunidades, como "sujeitos de ordem superior", na designação de Husserl, ou se quisermos, é do mundo da vida, enquanto mundo intersubjetivo, que emergem estas formas da interação social e os sujeitos coletivos. Pertencem a essa consciência, tal como Husserl afirma e nós concordamos, as "formas normativas da «razão»" existindo, simultaneamente a priori, "a possibilidade de as pensar livremente em geral e, de acordo com leis normativas apriorísticas auto reconhecidas, de as pensar no modo como elas nos determinarmos em geral para a prática". 9

4. A expressão destas leis apriorísticas, relativas à esfera da socialidade e da comunidade intersubjetiva, que podemos designar como princípios da coexistência e da convivência humanas, cremos encontrá-las nos chamados direitos humanos, e julgamos mesmo que são elas que constituem o seu cerne. Descrever fenomenologicamente a estrutura desses princípios é tarefa indispensável que se tem agora de realizar.

O primeiro princípio é a dignidade humana. Uma descrição fenomenológica deste princípio leva-nos a afirmar que a dignidade humana tem que ver com o sentido do mesmo, daquilo que é igual, que é a dimensão básica da apercepção de um outro enquanto outro eu.

Não no sentido da pura identidade, pois a realidade mostra-nos que somos diferentes, seja por condições económicas, culturais, sociais, ou outras, mas porque esta mesmidade faz parte da estrutura essencial da experiência intersubjetiva. A dignidade radica desde logo na intersubjetividade, uma vez que a intuição originária que tenho do outro é a de que ele está no mesmo plano que eu. Por isso, eu sou de imediato reenviado para o outro e o outro para mim. Podemos mostrar ainda que dignidade, enquanto igualdade, envolve o

\footnotetext{
7 Hua VI, 310.

${ }^{8}$ Hua, XXVII, 24 e ss.

${ }^{9}$ Hua, XXVII, 25.
} 
sentimento de respeito, ou seja, o sentido de uma presença que é para mim incontornável, que me leva a tratá-la como susceptível de atenção, e a atenção primeira que tenho para com o outro é a igualdade que reconheço nele. Esta igualdade não se adquire. Ela é originária.

Pelo fato de virmos ao mundo, temos já dignidade, logo, somos "dignos ou iguais". A dignidade do outro, e a minha dignidade perante o outro, está sempre relacionada com o reconhecimento recíproco, que é pedra angular da intersubjetividade. A dignidade do homem, cujo correlato é o respeito, afirma-se pelas ideias conexas de liberdade e de responsabilidade. Advertimos que não estamos a falar do exercício concreto da liberdade, mas de uma "liberdade eidética", inscrita na legalidade que regula a interferência intersubjetiva das possíveis condutas humanas.

Podemos acrescentar que esta liberdade é uma determinação de essência. A essência da liberdade é a própria liberdade na sua possibilidade de realização. Esta é, segundo Husserl, uma "liberdade de razão", desenvolvendo-se segundo as ideias de responsabilidade e de vida autêntica, liberdade criadora de valores que se autojustifiquem absolutamente, os quais permitem avaliar a ação fáctica segundo um fundamento racional e não já contingente, relativo a um qualquer universo cultural preso na finitude. Só a liberdade da razão cria "a consciência de responsabilidade da razão ou da consciência ética". ${ }^{10}$ Justamente, estes princípios referidos apontam para o que há de mais elevado no homem, a intuição racional do justo ou do injusto, do bom ou do mau, para lá de todos os circunstancialismos. E, como podemos concluir, é o homem que é sujeito e objeto dessa responsabilidade da razão, que já não se traduz como mera escolha individual, mas o envolve num projeto que implica o "combate pela clareza, pela verdade, pelo direito [...]", ${ }^{11}$ o qual conduz à comunidade e em última instância à realização de um ideal de humanidade. Sem essa responsabilidade, a liberdade não passaria de libertinagem, pois o homem ao ser responsável pela sua decisão, toma $o$ ato como seu. De onde se segue que a dignidade, postulando os restantes princípios, significa que toda a pessoa humana é merecedora de respeito por ser um ser moral, livre, autónomo e responsável. Podemos, quiçá, afirmar que os direitos humanos e os direitos fundamentais são, por convergência, a manifestação da dignidade e da liberdade ou autonomia do homem. Assim, devem as constituições promover e integrar os direitos humanos.

5. Feitas estas breves considerações, fica por responder de que modo são os direitos humanos expressão do direito natural.

11 Hua VI, 56 
Antes de mais, convém salientar a seguinte ideia: entendemos que os direitos humanos envolvem em si uma questão jurídica e política. Não nos interessa aqui elencar os direitos humanos nas suas diferentes gerações, mas compreender como podem ser, ao mesmo tempo, um direito natural e um princípio de constituição da ordem normativa. $\mathrm{Na}$ verdade, os seus princípios são tão relevantes que urge salvaguardá-los. Essa salvaguarda só pode ser dada na constituição dos estados. É o que acontece na nossa Constituição quando lemos expressões como "garantir os direitos fundamentais dos cidadãos", "república soberana, baseada na dignidade da pessoa humana", ou ainda, "Portugal rege-se nas relações internacionais pelos princípios [...] do respeito dos direitos do homem [...]". ${ }^{12}$

A questão é esta: como podemos conciliar uma natureza humana universal, inerente ao direito natural, fundada numa teoria do eidos "homem e sua vida intersubjectiva", com a historicidade e pluralidade de sentimentos e visões? Não haverá aqui contradição? Reconhecemos que o nosso tempo não tem sido fácil. Vivemos no início de um milénio conturbado e contraditório. Período de desconcerto, gerador de uma crise de valores culturais, que atinge o direito e a política. Positivismo jurídico, agnosticismo, relativismo, naturalismo jurídico, pragmatismo jurídico e social, perspetivas que, como salienta Castanheira Neves e com o qual estamos de acordo, vão no sentido de proclamar que o direito tem uma finalidade social e uma instrumentalização ao político. Estas perspetivas conduzem à negação da autonomia humana, pelo que a pessoa, longe de ser um fim em si mesma, perde a possibilidade de participação e de responsabilidade comunitária, para ser instrumento de realização colectiva. $\mathrm{E}$, à custa desse coletivo, quantos atropelos, trágicos destinos e injustiças se realizaram! Não mostra a realidade, e estas correntes, nem direitos humanos, nem direito natural?

Parecendo que sim, afirmamos que não. Sem dúvida que o mundo jurídico é um mundo de decisão. A decisão implica o diálogo entre os espíritos, fruto do raciocínio prático, sem o qual nenhuma ação seria possível. Tempo e história são indissociáveis deste raciocínio. Nesta indissociabilidade, desenrola-se a vida jurídica como vida atual, dinâmica e criadora. Assim, o tempo jurídico é indissociável do ser jurídico. Dito de outro modo, o presente manifesta a experiência jurídica, contendo, simultaneamente, em si as infinitas possibilidades dessa mesma experiência. Nesta medida, o mundo jurídico é o resultado de um consenso entre várias partes. Consenso que implica diálogo perante um certo auditório, o qual, investido do poder, legitima a escolha de certa norma. A norma é, pois, o resultado de uma decisão em detrimento de 
outra norma. Em termos idênticos a Husserl, a verdade dos argumentos exprime uma certeza-crença. Nesta convergência do conhecer e do agir, falamos de objetividade da vida, a qual se desdobra em múltiplas interpretações. Em vista disso, a diferença que podemos apontar entre as várias convições que apontam para as formas de verdade-certeza é qualitativa e não de grau. Deste modo, na decisão, ou na aplicação da norma, a lógica jurídica não atende apenas à análise dos esquemas argumentativos, mas opera dentro de um contexto em que é fundamental o respeito pelas regras de direito (seja de conteúdo, seja de processo).

Ora, o respeito das regras, a segurança jurídica, a procura da verdade e de resposta às situações-limite, a proteção dos inocentes, a defesa das relações de confiança entre os sujeitos e, até, entre os estados, devem ser consonantes com o respeito pela pessoa humana, consequentemente, com o respeito pelos direitos humanos. Com efeito, se estes elementos são estranhos a uma lógica jurídica formal, são a pedra de toque de uma lógica jurídica entendida. ${ }^{13}$ No seguimento destas análises, concluímos que o mundo jurídico faz parte da cultura. Acolhemos a região ôntica de realidade proposta por Husserl: o eidos homem e vida ética e social, inserto na região mundo cultural. Justamente, uma das características fundamentais dos objetos culturais está na identidade entre ser e sentido. Mas o sentido só é sentido quando significa algo para alguém, ou seja, os objetos culturais só são realidades valiosas para o homem. Essas realidades valiosas constituem o mundo da cultura, o qual manifesta não só o passado, mediante os valores, as crenças, os conhecimentos sedimentados numa tradição, só para citar alguns exemplos, como manifesta as intenções criadoras atuais.

O direito é, então, ser ideal, e o seu ser não se exaure nas manifestações reais que o representam. A essência do direito encontra-se, então, na condição de coexistência sem a qual não existe o humano. Dentro deste contexto, o ser do direito é a conduta em interferência intersubjetiva. O direito é fenómeno que aparece como resultado das relações de interesse entre os sujeitos. Os interesses pressupõem vontades, expetativas, intenções, e são, por isso, manifestações de valor, daí que a norma prescritiva, declarativa, proibitiva, ou outra, embora não seja um juízo de valor, pressupõe esse juízo, uma vez que exprime uma determinada decisão.

$13 \mathrm{Na}$ linha de Chaim Perelan entendemos a lógica argumentativa como, "lógica da controvérsia", que pretende "estabelecer, em cada caso de espécie, a preeminência de um ou outro valor", pois não está em causa a adequação cognitiva a um certo fato, nem se pretende justificar leis universais, uma vez que o domínio do direito se refere a convições. Sendo prático-emocional, é a dimensão da avaliação e da decisão, segundo o bem ou o mal, o justo ou o injusto, o direito ou o oblíquo, que está em causa. Cf. Chaim Perelman, Ética e Direito, Lisboa: Instituto Piaget; Chaim Perelman e Lucie Olbrechts-Tyteca, Tratado da Argumentação. A Nova retórica. Rio de Janeiro: Martins Fontes, 2002. 
6. Por conseguinte, o direito, como fenómeno cultural, tem densidade ontológica e axiológica. Acresce que não há cultura sem comunidade, como bem salientou Husserl: "a cultura é o conjunto das realizações que se efetivam nas atividades consecutivas do homem comunalizado, que têm uma existência espiritual permanente na unidade da consciência comunalizada e da sua tradição persistente". ${ }^{14} \mathrm{~A}$ comunidade radica nas relações intersubjetivas que emergem do mundo da vida. Por maioria de razão, o "eu" e o "outro" formam uma unidade-igualdade, sem a qual não seria possivel a manifestação da pessoa. Amar ou odiar, querer ou não querer, afirmar ou negar são atitudes comuns que têm de envolver, pelo menos, dois sujeitos; a língua, as instituições, as vivências religiosas e os ritos pressupõem um comum de sujeitos, e de tudo isso é constituída a comunidade. Salientando o que nos importa, a condição de coexistência, base de toda a intersubjetividade humana, da qual nascem os princípios da dignidade, igualdade e liberdade, radica no retorno à corporalidade, à physis na sua unidade com a psyche, base para todo o reconhecimento intersubjetivo. Não podemos pensar o espírito sem pensar o corpo onde ele assenta. "A pessoa é decerto localizada, e na verdade, por meio do seu corpo somático, corpóreo, no espaço natural e na temporalidade natural". ${ }^{15}$ O fundamento dos direitos humanos está assim nessa estrutura básica, na qual o homem se encontra como ser psicossomático e espiritual, desenvolvendo-se toda a sua ação no mundo circundante. Com efeito, como refere Husserl, na minha esfera, o outro apresenta-se em virtude de uma associação e do emparelhamento com o meu soma corpóreo e o eu psíquico que aí governa. Isto permite que eu me situe no lugar do outro, e vice-versa, "como se eu atuasse ali, no lugar do corpo somático alheio". ${ }^{16}$ Esta ideia de que, na apresentação do outro, há um analogon, a partir do qual os sistemas sintéticos da vida de consciência, com seus respectivos teores noemáticos, são os mesmos, embora em perspectividade convergente, permite-nos afirmar que todo o sistema juridico se fundamenta num sentido do justo ou do reto que dimana desta relação analógica, de diversidade convergente, em que o jurídico surge como o sentido da "afinação" ou de "ponto de convergência" que permite a coexistência das diferenças. O jurídico, nesse sentido de busca de uma convergência "reta" entre as diferenças, não é algo sujeito à historicidade. A história é mudança, permanecendo, porém, a procura do justo como dimensão de essência da vida intersubjetiva. Se é certo que "o sentir e o pensar de cada época são, sempre, o sentir e o pensar que nela, e só nela, são possíveis", todavia, a constituição 
e as disposições ontológicas desse sentir e pensar são imutáveis. Se assim não fosse, mudariam essas disposições. Logo, não estaríamos defronte das múltiplas manifestações históricas de um mesmo ser, mas perante manifestações de seres diferentes.

De onde se segue que é da essência humana a pessoa ser um ser jurídico: intersubjetividade é juridicidade, enquanto determinação do "justo" ou do "reto", sem o qual uma vida comum não seria possível. O carácter jurídico resulta da condição de coexistência. Deste modo, as declarações dos direitos humanos, mormente a de 1948, as constituições que evocam os direitos humanos, as convenções, os tratados, têm como fundamento originário a pessoa humana em coexistência ou em conexão intersubjetiva. Ela é a fonte de todo o direito, só o homem é, como no-lo dizia Heidegger, "um ser a caminho", e, por isso, ele é a fonte de toda a compreensão e interpretação possível.

7. Chegados aqui, importa esclarecer uma decisiva questão: a relação entre direitos humanos e direito natural.

Consideramos que os direitos humanos são direitos naturais. A dificuldade que se nos depara está em saber o que é, neste caso, o direito natural. A nossa tese é a seguinte, quando falamos de direitos humanos, referimo-nos, sobretudo, aos princípios pré-normativos que foram expostos, dignidade, liberdade e igualdade, os únicos que podem ser radicados na natureza psicossomática e intersubjetiva do homem.

Assim, a dignidade humana é o núcleo essencial dos direitos humanos, constituindo-se como seu critério interpretativo. Nesta sequência, os princípios que decorrem do reconhecimento da igualdade do outro, e vice-versa, a liberdade, indispensável para a realização da pessoa, são meios que conduzem à realização jurídica e política das comunidades. Então perguntamos o que pode ser fundamento do direito que vá para além da positividade inerente a todo o ordenamento jurídico, bem como à validez e eficácia da norma? O que nos permite acreditar que há um invariante, um para além de toda a historicidade e temporalidade jurídicas? O que leva à afirmação de que a Constituição, como instrumento de constituição do poder, tem fundamento em si mesma?

A resposta está nesse invariante que é a estrutura trina da pessoa humana que emerge do mundo da vida: a pessoa humana em interferência intersubjetiva. No que importa insistir, e retomando o conceito fenomenológico de mundo, somos chamados à verificação de que os homens convivem uns com os outros partilhando e comungando várias intencionalidades. Esta dimensão da intersubjetividade implica um fazer compartilhado, ou seja, tem como características a correlatividade e a reciprocidade, a que vai colada a 
exigibilidade, uma vez que eu, para poder usufruir da habitabilidade do mundo e me poder manifestar como pessoa, exijo determinadas condições aos outros, que por sua vez, num processo idêntico, me exigem igualmente determinadas condições. A significar tal afirmação que a condição mundana é, simultaneamente, condição natural e social, pois sem os outros (socii) nada disto seria possível. Sendo assim, podemos concluir que temos a condição primeira do aparecimento do direito, que é a condição social na qual os vários sujeitos interagem, manifestando pretensões e ações uns perante os outros, pelo que aquilo que é juridicamente possível, é, por isso mesmo, juridicamente exigível. E o que é exigível, em primeiro lugar, é o respeito e o reconhecimento do outro como pessoa, que é, a um tempo, condição transcendental e condição de possibilidade do direito, pois, sem o reconhecimento da pessoa, o direito seria impensável e não poderia existir. Por conseguinte, apesar de apresentar conteúdo positivo, o fundamento do direito não é um fato social mas eidético, pois o homem por essência tem capacidade para estabelecer relações jurídicas.

Consequentemente, esta essência não é a mesma afirmada pelas concepções jusnaturalistas essencialistas. A lei natural implica que no próprio ser do homem está a sua plenitude de ser como dever-ser, logo, a sua primeira expressão é a realização da liberdade. Esta é o princípio impulsionador de decisões que singularizam o homem no plano ontológico e axiológico, visando a dignidade humana. Por conseguinte, o direito e toda a ordem normativa deve contemplar o direito natural à liberdade, da qual proviriam o direito à vida, à integridade física, à expressão, etc. Daí a urgência de entender um novo direito natural centrado na ideia de dignidade do qual dependem os restantes valores jurídicos.

8. Ficou esclarecido que quando falamos de condição de coexistência falamos do seu resultado, que é a comunidade, o comum. Também já vimos que esta emerge do mundo da vida (Lebenswelt) que constitui o a priori da convivência e o a priori da linguagem. Decorre daqui que o direito natural constitui-se como direito-valor, pelo que, direito natural e direitos humanos articulam-se na vida natural dos homens, da qual emerge a cultura e a comunidade. A comunidade é sempre "comunidade-comunicativa" 17 co-constitutiva da natureza do homem, cujos princípios ordenadores e originários são os pressupostos essenciais da "comunicação" e da forma de vida do "homem". Estes constituem-se como meta-institucionais e não contingentes, revelam-se como princípios normativos suprapositivos. A validade de qualquer direito

${ }^{17}$ Cf. João Baptista Machado, Introdução ao Direito e ao Discurso Legitimador. Coimbra: Almedina. 
positivo estaria, pois, nesses princípios ordenadores originários transcendentes ao arbítrio humanos, como sejam os princípios da dignidade, da igualdade e da liberdade. Por um lado, apesar de se constituir como a priori do direito, esses princípios aparecem no plano prático-axiológico do existir humano, não dispensando a experiência jurídica concreta. Assim, e próximo de Castanheira Neves, sustentamos que estes princípios objetivam-se historicamente nos princípios regulativo-jurídicos, sendo o constituens de um válido ordenamento jurídico. A título de exemplo: os princípios da autonomia privada, de responsabilidade pelos danos; seguidamente, temos os princípios ético-jurídicos, ideológico-politicos e sócio-jurídicos, que são dados mediante a conversão à juridicidade de valores éticos ou padrões sociais, como a noção de boa-fé, dos bons costumes, etc.; por último, os princípios meramente jurídicos, que se impõem também como intenções regulativas. Portanto, estes princípios são constituintes da normatividade jurídica. ${ }^{18}$ Por outro lado, defendemos que o direito natural exprime o sentido do jurídico, e que é uma metodologia, ou seja, apresentar-se-ia como um método nessa busca constante e perpétua de justiça (constans et perpetua voluntas), manifestação primeira do direito natural.

Uma análise fenomenológica da justiça leva-nos a considerar que é a exigência de harmonia entre os sujeitos, sem a qual a realização da dignidade humana não é possível. Não podemos tratar aqui de tão complexo problema, por isso não vamos referir os critérios da justiça. São múltiplos e dependem de várias circunstâncias. Nem vamos abordar também as múltiplas definições de justiça, todas elas decerto importantes. Centramo-nos apenas em duas ideias que vamos somente enunciar.

Uma. Todas as definições de justiça apontam para a noção de igualdade. Deixando de lado as razões que justificariam a pluralidade deste princípio, afirmamos apenas que a justiça será "um princípio de ação segundo o qual os seres de uma mesma categoria essencial devem ser tratados da mesma maneira" 19

Outra. A justiça consiste em atribuir a cada um aquilo que é seu. Ora, não estará implícita nesta fórmula que o que é de cada um é a realização da sua liberdade? E nesse sentido, não significa a justiça a realização do ser próprio da pessoa, da sua dignidade? Por outras palavras, a justiça, fundamentada no emparelhamento originário, protoforma da sintese de associação que permite a génese do sentido do justo como forma de coexistência, constitui-se como uma intencionalidade normativa, significando que a norma jurídica deve visar o justo. Por isso, a justiça é o princípio que antecede e orienta a imposição do

${ }^{18}$ Cf. Castanheira Neves, "Fontes do Direito". Digesta, II, pp. 66 e ss.

19 Cf. Perelman, Ética e Direito, ed. cit., pp. 27 e ss. 
valor jurídico e, nessa medida, diz como o direito deve ser e exige-lhe determinado conteúdo. Ambos, forma e conteúdo do jurídico, estão-lhe subordinados.

Por conseguinte, como princípio de realização da pessoa, a justiça manifesta-se nas situações concretas, seja em termos de intenções específicas, seja em termos de intenções ético-políticas. Assim considerada, a justiça não é virtude ou princípio subjectivo, mas é a justiça como princípio, o mesmo é dizer, fundamento de um juízo de validade, portanto, como princípio objetivo.

9. Significam estas considerações que defendemos que os direitos humanos se manifestam nos direitos fundamentais, pois estes tendem à preservação da dignidade e consequente proteção da pessoa humana, e, nessa linha, os direitos fundamentais devem ser fundamentados na essência humana. Nessa medida, julgamos que o direito natural, ou o eidos direito, deve fazer parte constituinte do Direito, e por isso devem estar protegidos nas constituições e nas normas; caso contrário, correm o risco de serem considerados como simples princípios de boas intenções, sem serem levados a sério.

Consideramos que os direitos humanos não são direitos subjetivos no sentido positivista, visam todo o homem, e nessa medida transcendem a ordem jurídica. São, igualmente, do domínio da política, por isso, encontram nas declarações, constituições, convenções, suporte de aceitação, as quais remetem para a importância da sua salvaguarda e necessária positividade. Mas aceitamos que os princípios normativos dos direitos humanos são direito natural fundado na lei eidética de coexistência entre os homens, e que estão plasmados nos direitos fundamentais. Por isso, a nossa resposta à questão a que nos propusemos é esta: os direitos humanos são direito natural (eidético) e o direito natural é fundamento da normatividade.

\section{ABSTRACT}

The justification of Natural Law is a very controversial issue, not only after the Positivist's rebuttals, but since its very anthropological foundations in the early modern age. In this paper, I try do give an account of Natural Law and natural rights in terms of a phenomenological description of the background of normative intentionality. Taking a genetic stance, I go from the positive norm and the intentionality that constitutes it to the underling pregiveness that supplies the condition of its possibility. I exhibit it as the experience of the live-world, and I analyze it as an intersubjective world, where persons are given as equals and worth-counting. This is the very root of the concept of human dignity. Starting from it, I develop an account of the sense and content of the concept of Human Rights as a set of eidetic laws creating the framework for authentic human relationships. 